\title{
Análisis de la Expresión de Receptores de Estrógenos y Progesterona en el Endometrio de Ovejas de las Razas Romney Marsh y Araucana
}

\author{
Analysis of the Expression of Estrogen and Progesterone Receptors \\ in the Endometrium of Ewes of the Races Romney Marsh and Araucana
}

*,**Adriana Vasconcellos C.; ***Marco Paredes H; ${ }^{* * * *}$ Johanna Carrasco R. \& *** Daniela Núñez R.

VASCONCEllos, C. A.; PAREDES, H. M.; CARRASCO, R. J. \& NÚÑEZ, R. D. Análisis de la expresión de receptores de estrógenos y progesterona en el endometrio de ovejas de las razas Rommey Marsh y Araucana. Int. J. Morphol., 27(1):97-100, 2009.

RESUMEN: El estado morfofuncional del tracto genital de las ovejas hembra es determinado por las hormonas sexuales, las que actúan a través de receptores específicos. Éstos regulan la expresión de numerosas proteínas comprometidas en el desarrollo del endometrio. Posiblemente, el desempeño reproductivo de diferentes razas de ovejas podría estar determinado por la expresión diferencial de los receptores. El objetivo del presente estudio fue analizar la presencia de receptores de estrógenos (RE) y progesterona (RP) en el endometrio de ovejas prepúberes y en ciclo, de las razas Romney Mash y Araucana. La histología del endometrio se realizó en cortes de $5 \mu \mathrm{m}$ teñidos con hematoxilina y eosina. La presencia de ambos receptores se detectó mediante inmunohistoquímica, utilizando anticuerpos monoclonales específicos. Además, se evaluó por Dot-blot la presencia de los receptores en extractos proteicos totales obtenidos a partir de tejido endometrial. Se detectó señal inmunorreactiva contra ambos receptores en borregas y adultas ciclando, de ambas razas. Destacó la inmunorreacción positiva en núcleos de células estromales y del epitelio glandular. Los RE en ovejas adultas presentaron mayor expresión que en las prepúberes, no encontrándose diferencias significativas entre ambas razas. Los RP presentaron inmunorreacción positiva en ambas razas, siendo la señal levemente más fuerte en las borregas Romney Marsh, mientras que, en ovejas adultas se observó mayor señal en Araucanas. Concluimos que la expresión inmunohistoquímica de RE y RP fue detectable en el endometrio de las ovejas, variando su expresión según la etapa de desarrollo y estadio reproductivo, no pesquisándose diferencias significativas entre ambas razas.

PALABRAS CLAVE: Ovejas; Endometrio; Receptor estrógeno; Receptor progesterona; Razas.

\section{INTRODUCCIÓN}

La reproducción animal es modulada por hormonas sexuales y sus receptores, cuyos niveles de expresión varían entre las distintas especies. (Cunningham, 1998; Priedkkalns, 1993; Meikle et al., 2004). En ovinos, los estrógenos y progesterona tienen efecto a nivel del aparato reproductor de la hembra, animal poliéstrico estacional, en el cual se han descrito cambios que inducidos en el útero durante el periodo fetal, neonatal (Wiley et al., 1987) y durante sus fases reproductivas (Meikle et al., 1997; Meikle et al., 2001; Meikle et al., 2004; Vasconcellos et al., 2006). A diferencia de otros mamíferos como los canidos (Vasconcellos et al., 2008), en el endometrio de las ovejas la presencia de receptores de estrógenos y progesterona fisiológicamente activos se encuentran desde la etapa prepuberal (Garofalo \& Tasende, 1996; Meikle et al., 2001). Comenzada la actividad ovárica las hormonas sexuales y sus receptores inducen cambios que se producen en el endometrio durante el ciclo estral (Cherny, 1991; Meikle et al., 2001 y Spencer \& Bazer, 1995).

No existen estudios en los cuales se hayan analizado variaciones en la expresión molecular de los receptores de estrógeno (RE) y progesterona (RP) entre razas distintas. Posibles diferencias en el nivel de expresión de estos recep-

* CEBIOR (Centro Biotecnológico de la Reproducción), Facultad de Medicina, Universidad de la Frontera, Temuco, Chile.

** Depto.Ciencias Básicas, Facultad de Medicina, Universidad de la Frontera, Temuco, Chile.

****:Escuela de Medicina Veterinaria, Facultad de Recursos Naturales, Universidad Católica de Temuco, Chile.

Financiado por Proyecto DIUFRO 107-0017. Facultad de Medicina, Universidad de la Frontera, Temuco, Chile. 
tores entre razas podría estar relacionado con características morfo-funcionales distintas.

El objetivo del presente estudio fue evaluar la expresión inmunohistoquímica de los RE y RP en el endometrio de ovejas prepúberes y ciclando, de dos razas distintas.

\section{MATERIAL Y MÉTODO}

Se utilizaron seis ovejas de la raza Romney Marsh y seis de raza Araucana (2 prepúberes y 4 ciclando, de cada raza). Después del sacrificio, se tomaron muestras de útero: cuernos en corte transversal y cuerpo en corte longitudinal. La mitad de las nuestras fueron fijadas en Bouin acuoso, para su estudio histológico y la otra parte se congeló en nitrógeno líquido para extracción de proteínas. Las muestras fijadas se incluyeron en Paraplast (Histhosec, Merck, Alemania) y se prepararon cortes de 5 a 7 micras. Los cortes fueron teñidos con hematoxilina y eosina (Merck, Alemania) y posteriormente, analizados histológicamente. El procesamiento inmunohistoquímico (ICQ) de los cortes comenzó con la eliminación de la actividad de peroxidadas endógenas, incubando con $\mathrm{H}_{2} \mathrm{O}_{2}$ al $3 \%$ en metanol, por 10 minutos. Se lavó luego, dos veces con PBS por 5 minutos y se procedió a incubar en solución de bloqueo (BSA 1\%, leche descremada 5\%, tritón X-100 0,3\% en PBS) a temperatura ambiente, por $30 \mathrm{~min}$. Se incubaron a continuación con un anticuerpo anti-RP y anti-RE diluido 1:500 en solución de bloqueo, durante toda la noche, a temperatura ambiente. Posteriormente, los cortes se lavaron 3 veces, por 5 minutos con PBS. Se utilizó el sistema de detección LSABTM Kits (Dako, USA) que se basa en el reconocimiento del primer anticuerpo por un segundo anticuerpo anti-IgG, conjugado a biotina, el cual es posteriormente reconocido por el complejo estreptoavidina-peroxidasa. El revelado se realizó incubando en $40 \mathrm{ml}$ de solución de revelado (DAB 0,5\% y perhidrol $1 \mathrm{ml} / \mathrm{ml}$ en PBS) a temperatura ambiente, por 5 a 10 minutos. El portaobjeto con corte histológico, se lavó con agua destilada y seguidamente se tiñó para contraste con hematoxilina. Seguidamente, se deshidrató en una batería creciente de etanol (50 a 100\%), luego se diafanizó con xilol y finalmente se montó para análisis microscópico, utilizando un microscopio (Leitz, Laborlux 12).

\section{RESULTADOS}

El análisis histológico del endometrio de ovejas prepúberes, muestra zonas carunculares y áreas intercarunculares-glandulares (Fig. 1A). En oveja ciclando el endometrio de la zona intercaruncula presenta mayor número de glándulas y de estructura más tortuosa. La inmuno-detección de los receptores por Dot-blot indicó la presencia de RE y RP, tanto en borregas como en ovejas adultas (Figs. 1B y 1C). El análisis ICQ de RE y RP destacó señales inmu-norreactivas nucleares del estroma caruncular, de los epitelios glandular y de revestimiento (Figs. 2A, 2B, $3 \mathrm{~A}$ y $3 \mathrm{~B}$ ). Los RE en ovejas adultas, presentan mayor expresión que en las prepúberes, no habiendo diferencias marcadas entre ambas razas. Los RP dieron inmunorreacción positiva en ambas razas, siendo aparentemente, la señal levemente más fuerte en borregas Romney Marsh, mientras que en ovejas adultas se observó mayor señal en raza Araucana.

\section{DISCUSIÓN}

En la práctica veterinaria, es importante la determinación de niveles plasmáticos de hormonas esteroidales sexuales para el diagnóstico de disfunciones reproductivas en animales domésticos, incluyendo al bovino y ovino (Cunningham). Sin embargo, también es necesario evaluar la expresión y distribución de los receptores sobre las que ellas actúan. Su manejo podría modificar su comportamiento reproductivo y por lo tanto, su potencial productivo (Sepúlveda et al., 2007). No se debe olvidar además, que se ha generalizado el empleo de hormonas sexuales sintéticas para producir inducción del celo y sincronizaciones, como métodos para mejorar la eficiencia reproductiva. Estos fármacos actuarían sobre los receptores activándolos y generando una respuesta fisiológica cuya magnitud dependería del nivel y lugar de expresión de las proteínas receptoras en el sistema reproductivo. La expresión de RE y RP en animales prepúberes se ha detectado anteriormente, en ovejas de la raza Corriedale (Garofalo \& Tasende) y Romney Marsh (Meikle et al., 1997, Meikle et al., 2004, Vasconcellos et al., 2005). Nuestros datos evidencian también que estos receptores son expresados en endometrio de ovejas de raza Araucana, aparentemente con la misma intensidad que en ovejas Romney Marsh. A diferencia de otros mamíferos, como el perro, en el cual no es posible evidenciar RE y RP en la etapa prepuberal (Vasconcellos et al., 2006 ), en las ovejas la expresión de estos receptores en estado fisiológicamente activo es evidenciable. En animales adultos, se han encontrado RE en sus dos isoformas:alfa y beta. Se sostiene que alfa es el receptor proteico que media la clásica acción estrogénica en el tracto reproductivo aunque se han identificado también receptores estrogénicos de la isoforma beta en útero y principalmente en ovarios (Ing \& Ott, 1999 ). Durante el ciclo estral ovino, en el endometrio los recepto- 


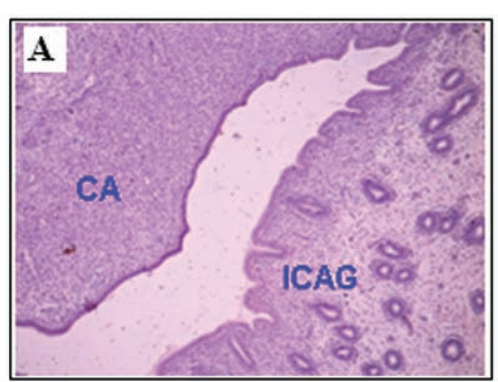

B

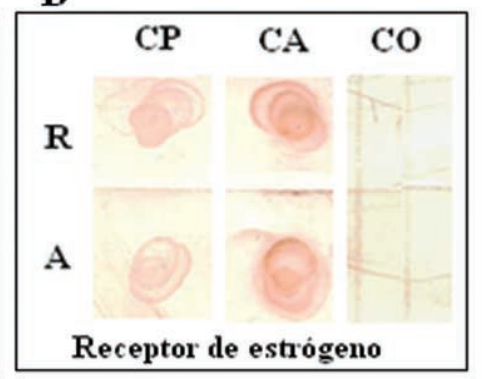

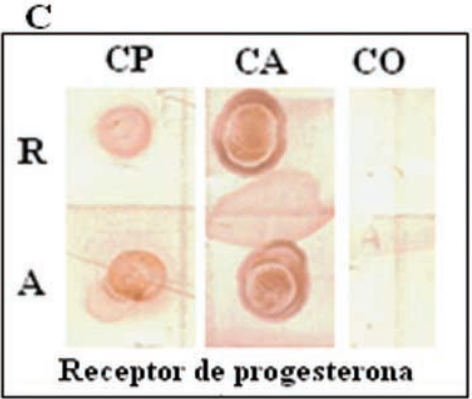

Fig. 1. A) Corte transversal de cuerno uterino de oveja (A), se destaca la región caruncular (CA) e intercaruncular-glandular (ICAG). Inmunodetección por Dot-blot del receptor de estrógeno (B) y progesterona $(\mathrm{C})$ en extractos de proteínas totales de cuerno de ovejas pre-púberes $(\mathrm{CP})$ adultas $\mathrm{CA}$ ) y de las razas Romney Marsh (R) y Criolla Araucana (A). Control negativo (CO).
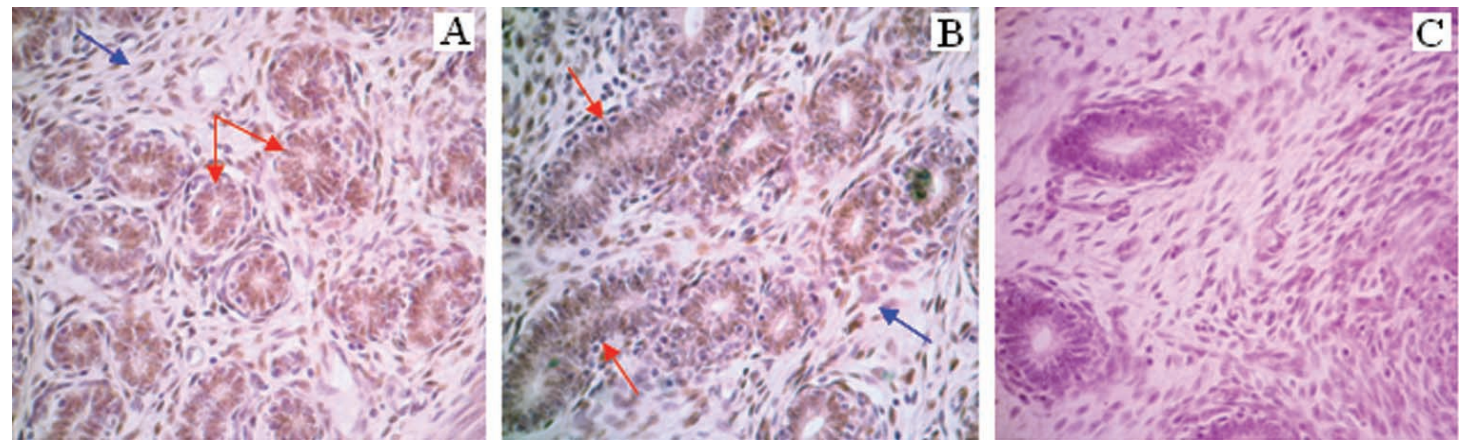

Fig. 2. Inmunohistoquímica para receptor de estrógeno en endometrio. A): Oveja prepuber. B) Oveja adulta C) Control negativo. Las flechas de color rojo indican células inmunoreactivas en glándulas endometriales y las azules en células del estroma endometrial.
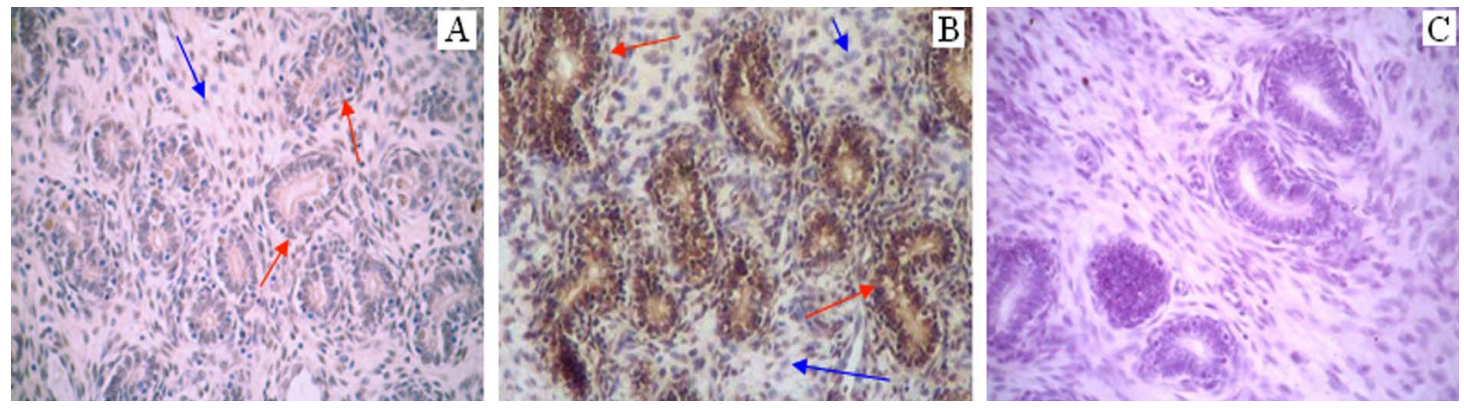

Fig. 3. Inmunohistoquímica para receptor de progesterona en endometrio. A): Oveja prepuber. B) Oveja adulta C) Control negativo. Las flechas de color rojo indican células inmunoreactivas en glándulas endometriales y las azules en células del estroma endometrial.

res de estrógenos y progesterona muestran una elevación corta después del estro y declinan hasta hacerse indetectables en la mitad de la fase lútea. (Meikle et al., 1997, 2004; Vasconcellos et al., 2005 a y b, 2006).

El nivel marcado de expresión de RE y RP en ovejas adultas de ambas razas indicaría que los animales se encontraban en la fase estro-metaestro del ciclo, lo cual podría estar relacionado, con el periodo del año (abril-otoño) en que los animales fueron sacrificados teniendo en cuenta su estacionalidad reproductiva. Se concluye que la expresión de RE y RP es siempre detectable en el endometrio de las ovejas, variando la intensidad de su expresión según su etapa de desarrollo y estadio reproductivo, no encontrándose diferencias significativas entre las razas Romney Marsh y Araucana. 
VASCONCELlOS, C. A.; PAREDES, H. M.; CARRASCO, R. J. \& NÚÑEZ, R. D. Analysis of the expression of estrogen and progesterone receptors in the endometrium of ewes of the races Rommey Marsh and Araucana. Int. J. Morphol., 27(1):97-100, 2009.

SUMMARY: The morphofuncional state of the genital tract of females ewes is determined by sexual hormones, those that act through specific receptors. These regulate the expression of numerous proteins that participate in the development of the endometrium. Possibly the reproductive performance of different races from ewes could be determined by the expression differential of the receptors. The objective of the present study was to analyze the presence of estrogen receptors (RE) and progesterone receptors(RP) in the endometrium of prepuberal and cycling ewes of the races Romney Mash and Araucana. The histhologic study of endometrium was made in cross sections of $5 \mathrm{~mm}$ stained with hematoxilina-eosin. The presence of both receptors is detect by immunohistochemical study using monoclonal antibodies. In addition we evaluated by Dot-blot the presence of receptors in total protein extracts obtained from endometrial tissue Inmunoreaction signal against both receptors in lambs was detected and in adults cicling of both races The positive inmunoreaction is localizate in nuclei of estromales and glandular epitelium cells. The RE in adult ewes showed greater expression that in prepuberal, without significant differences between both races. The RP gave positive inmunoreaction in both races, being the signal more marcate in Romney Marsh lambs, while that in adult ewes higher signal was observed in Araucanas. We conclude that the immunohistochemistry expression of RE and RP is always detectable in the endometrium of the ewes varying his expression according to its development and reproductive stage, not significant differences were observed between both races.

\section{KEY WORDS: Ewes; Endometrium; Estrogen receptors; Progesterone receptors; Races.}

\section{REFERENCIAS BIBLIOGRÁFICAS}

Cunningham, J. Ciclos reproductivos en Fisiología Veterinaria. Mc Graw-Hill, Méjico, 1998. pp. 494-502.

Cherny, R. A. Inmunohistochemical localization of estrogen receptors in the endometrium of the ewe. Reprod. Fertil. Dev., 3:32131, 1991.

Garofalo, E. G. \& Tasende, C. Uterine estrogen and progesterone receptors in prepuberal ewe: distribution in myometrium, endometrium, and caruncles. Vet. Res., 27:177-83, 1996.

Ing, N. H. \& Ott, T. L. Estradiol up-regulates estrogen receptor- a messenger ribonucleic acid in sheep endometrium by increasing its stability. Biol. Reprod., 60:134-9, 1999.

Meikle, A.; Garófalo, E. G; Tasende, C.; Rodríguez,-Piñón; .; Shalin, L. Regulation by gonadal steroids of estrogen and progesterona receptors along the reproductive tract in female lambs. Acta Vet. Scand., 42:161-9, 2001.

Meikle, A.; Tasende, C.; Rodríguez, M. \& Garófalo, E. G. Effects of estradiol and progestern on the reproducive tact and onn uterine sex esteroid receptors in female lambs. Theriogenology, 48:1105-1113. 1997.

Meikle, A.; Tasende, C.; Sosa, C. \& Garófalo, E. G. The rol of sex steroid receptors in sheep female reproductive physiology. Reprod. Nutr. Dev., 16:385-94. 2004.

Priedkkalns, J. Sistema reproductor femenino. En: Dellmann, D. Histología Veterinaria. 2a Ed. Editorial Acribia, Madrid, 1993.

Sepúlveda, N.; Inostroza, K.; Bravo, S.; Rodero, E. \& Herrera, M. Comportamiento reproductivo y productivo de ovinos Romney Marsh y Araucanos en Chile. XXII Jornadas Científicas y XI Jornadas Internacionales Sociedad Española de Ovinotecnia y Caprinotecnia. Septiembre 2007, Mallorca.
Spencer, T. E. \& Bazer, F.W. Temporal and spatial alterations in uterine estrogen receptor and progesterone receptor gene expression during the estrous cycle and early pregnancy in the ewe. Biol. Reprod., 53:1527-43, 1995.

Vasconcellos, A.; Peña, P. \& Sepúlveda, N. Estudio histomorfológico comparativo del endometrio de la oveja prepúber y en anestro bajo influencia hormonal cíclica. Rev. Cient. FCV-LUZ., 15(4): 334-7, 2005.

Vasconcellos, A.; Sepúlveda, N.; Castillo, J.; Rosas,C. Presencia de receptores de estrógeno y de progesterona en el endometrio de ovejas prepúberes. Estudio inmunohistoquímico. Int. J. Morphol., 23(4):393-6, 2005.

Vasconcellos, C. A.; Sepúlveda, B. N.; Pacheco C. C. \& Miska, W Detección de receptores de estrógeno, progesterona y CBG (corticosteroid binding globulin) en el tracto genital de hembras caninas (Cannis familiaris). Estudio inmunohistoquímico. Rev. Cient. FCV-LUZ,18 (4):262-6, 2008

Vasconcellos, C. A.; Sepúlveda, B. N. \& Pacheco, C. C Presencia de receptores de estrógeno, progesterona y de $\mathrm{CBG}$ en el tracto genital de ovejas y de perras. Estudio inmmunocitoquímico. Int. J. Morphol, 24 (3):457-62, 2006.

Wiley, A. A.; Bartol, F. F.; Barron, D. H. Histogenesis of the ovine uterus J. Anim. Sci., 64:1262-9, 1987.

Dirección para correspondencia:

Dra. Adriana Vasconcellos Costa

Facultad de Medicina

Universidad de La Frontera

Casilla 54- D

Temuco - CHILE

Email. avascon@ufro.cl

Recibido: 22-09-2008

Aceptado:14-11-2008 